\title{
Validation of ground penetrating radar full-waveform inversion for field scale soil moisture mapping
}

\author{
Julien Minet*1 ${ }^{* 1}$ Patrick Bogaert ${ }^{1}$, Marnik Vanclooster ${ }^{1}$, and Sébastien Lambot ${ }^{1,2}$ \\ ${ }^{1}$ Earth and Life Institute, Université catholique de Louvain, Croix du Sud 2 BP 2, \\ B-1348 Louvain-la-Neuve, Belgium \\ ${ }^{2}$ Agrosphere (IBG-3), Institute of Bio- and Geosciences, Forschungszentrum Jülich \\ GmbH, D-52425 Jülich, Germany
}

February 22, 2011

\begin{abstract}
Ground penetrating radar (GPR) is an efficient method for soil moisture mapping at the field scale, bridging the scale gap between small-scale invasive sensors and large-scale remote sensing instruments. Nevertheless, commonly-used GPR approaches for soil moisture characterization suffer from several limitations and the determination of the uncertainties in GPR soil moisture sensing has been poorly addressed. Herein, we used an advanced proximal GPR method based on full-waveform inversion of ultra-wideband radar data for mapping soil moisture and uncertainties in the soil moisture maps were evaluated by three different methods. First, GPRderived soil moisture uncertainties were computed from the GPR data inversion, according to measurements and modeling errors and to the sensitivity of the electromagnetic model to soil moisture. Second, the reproducibility of the soil moisture mapping was evaluated. Third, GPR-derived soil moisture was compared with ground-truth measurements (soil core sampling). The proposed GPR method appeared to be highly precise and accurate, with spatially averaged GPR inversion uncertainty of 0.0039 $\mathrm{m}^{3} \mathrm{~m}^{-3}$, a repetition uncertainty of $0.0169 \mathrm{~m}^{3} \mathrm{~m}^{-3}$ and an uncertainty of $0.0233 \mathrm{~m}^{3} \mathrm{~m}^{-3}$ when compared with ground-truth measurements. These uncertainties were mapped and appeared to be related to some local model inadequacies and to small-scale variability of soil moisture. In a soil moisture mapping framework, the interpolation was found to be the determinant source of the observed uncertainties. The proposed GPR method was proven to be largely reliable in terms of accuracy and precision and appeared to be highly efficient for soil moisture
\end{abstract}

*julien.minet@uclouvain.be mapping at the field scale.

\section{Introduction}

The importance of accurate soil moisture characterization at various temporal and spatial scales for hydrologic, climatic and agriculture applications has boosted the development of different soil moisture sensing techniques. Review of soil moisture measurements techniques, including descriptions of the sensors, applications and research outlooks are given by Robinson et al. (2008a,b) and Vereecken et al. (2008). A particular development of remote sensing of soil moisture technologies was observed in the recent years (Wagner et al., 2007). At a much smaller support scale, invasive sensors such as time domain reflectometry (TDR) and capacitance probes are revealing their best potentialities in recently deployed wireless sensors networks (Bogena et al., 2010) that allow to collect huge amount of soil moisture data with an unprecedented temporal resolution. Nevertheless, the small sampling volume of these invasive sensors $(\sim \mathrm{dm})$ can be hardly compared with the larger footprint of the remote sensing instrument, even for high-resolution active radar sensors $(\sim 10$ $\mathrm{m}$ ), given the inherent high spatial variability of soil moisture at the radar footprint scale.

With an intermediate support scale $(\sim \mathrm{m})$, ground penetrating radar (GPR) for soil moisture sensing may bridge the scale gap between invasive sensors and remote sensing instruments. A review about recent GPR developments can be found in Slob et al. (2010) while a complete review of GPR applications for soil moisture sensing was given in Huisman et al. (2003). Numerous studies used the now well-established GPR ground-wave techniques for soil moisture determination (e.g., Huisman et al., 
2002; Grote et al., 2003; Galagedara et al., 2005; Lunt et al., 2005; Grote et al., 2010). Recently, some authors proposed innovative soil moisture retrieval techniques using the same GPR sensors. In that respect, van der Kruk (2006) and van der Kruk et al. (2010) developed an inversion method of dispersed waveforms trapped in a surface waveguide (i.e., when soil is layered by freezing, thawing or by a wetting front) for retrieving its dielectric permittivity and thickness. Benedetto (2010) used a Rayleigh scattering based method for directly determining the soil moisture, without the need of a petrophysical relationship and calibration of the GPR system.

Off-ground (i.e., proximal or air-launched) GPR systems offer particularly promising perspectives in terms of proximal soil sensing, as antennas can be rapidly moved over the soil surface when mounted on mobile platforms. Using an approach similar to satellite remote sensing of soil moisture, the retrieval of soil moisture using off-ground GPR is based on the measurement of the soil surface reflection. Few studies have applied such an off-ground GPR approach for soil moisture sensing in field conditions (Chanzy et al., 1996; Redman et al., 2002; Serbin and Or, 2003, 2005). Based on a full-waveform inversion of the GPR data and an accurate GPR system modeling, the off-ground GPR system developed by Lambot et al. (2004, 2006b) has shown excellent potentialities for surface soil moisture sensing and mapping in field conditions (Weihermüller et al., 2007; Lambot et al., 2008; Jadoon et al., 2010a; Jonard et al., 2010; Minet et al., 2011). The method relies on an accurate radar model that, in particular, accounts for the antenna and antenna-soils interactions.

The validation of the GPR technology for soil moisture retrieval implies a comprehensive assessment of the uncertainties in retrieval methods. The methods for assessing the uncertainties vary greatly in the literature, furthermore depending on the GPR system. Most of the studies attempted to calibrate or validate GPR measurements by comparing the GPR estimates with another measurement technique assumed to be the ground-truth (mainly TDR or soil sampling). Using the ground-wave technique, Huisman et al. (2001) compared GPR and TDR estimates of soil moisture with gravimetric sampling measurements and found similar root mean square error (RMSE) around $0.03 \mathrm{~m}^{3} \mathrm{~m}^{-3}$. The sources of errors were also identified and the dominant error was attributed to the petrophysical relationship. In controlled laboratory conditions, Lambot et al. (2004) found a very low RMSE of $0.0066 \mathrm{~m}^{3} \mathrm{~m}^{-3}$ between water content from sampling measurements and off-ground GPR using a linear approximation of the frequency-dependent effective electrical conduc- tivity. However, in field conditions and using the same off-ground GPR, Jadoon et al. (2010a) found a RMSE of $0.025 \mathrm{~m}^{3} \mathrm{~m}^{-3}$ between TDR and GPR estimates. The errors were mainly attributed to the different support scales of the instruments with respect to the small-scale within-field variability. As well as for remote sensing, the different support scales and the large vertical and lateral variations of soil moisture in real conditions may actually preclude the use of small-scale ground-truthing to fully validate the GPR sensors for soil moisture.

In that respect, Jacob and Hermance (2004) assessed the reproducibility of GPR common midpoint (CMP) measurements using information from the same CMP measurements and from several independent CMP measurements performed at the same location. Using a cross-borehole GPR, Alumbaugh et al. (2002) obtained a RMSE in volumetric soil moisture of $0.005 \mathrm{~m}^{3} \mathrm{~m}^{-3}$ between repeated measurements. Recently, Bikowski et al. (2010) and Minet et al. (2010b) assessed the posterior distributions of GPR-derived soil properties by a Markov Chain Monte Carlo technique in GPR inversion frameworks. This permitted to quantify confidence intervals around the inverted parameters by accounting for errors associated with the GPR data processing.

In this study, we propose to comprehensively evaluate the reliability of the GPR system developed by Lambot et al. (2004) for soil moisture mapping in field conditions and to quantify the soil moisture uncertainties. A mobile proximal GPR was used over a 2.5 ha agricultural field to map the soil moisture at high spatial resolution. We evaluated the reliability of the GPR technique by three independent uncertainty assessment methods. First, soil moisture uncertainties were derived from the inversion of the GPR data for each point by the computation of modeling error and soil moisture sensitivity. Second, three repetitions of the acquisition were performed, in order to assess the reproducibility of the technique, by comparison with the spatial interpolation uncertainties. Third, soil moisture core sampling were performed in order to compare the GPR estimates with reference soil moisture measurements, allowing for the evaluation of the petrophysical model. These three independent soil moisture uncertainty assessment methods were compared and the different sources of errors were identified.

\section{Materials and Methods}

\subsection{Study site}

We surveyed a 2.5-ha agricultural field situated in the loess belt area in the center of Belgium (Long. 


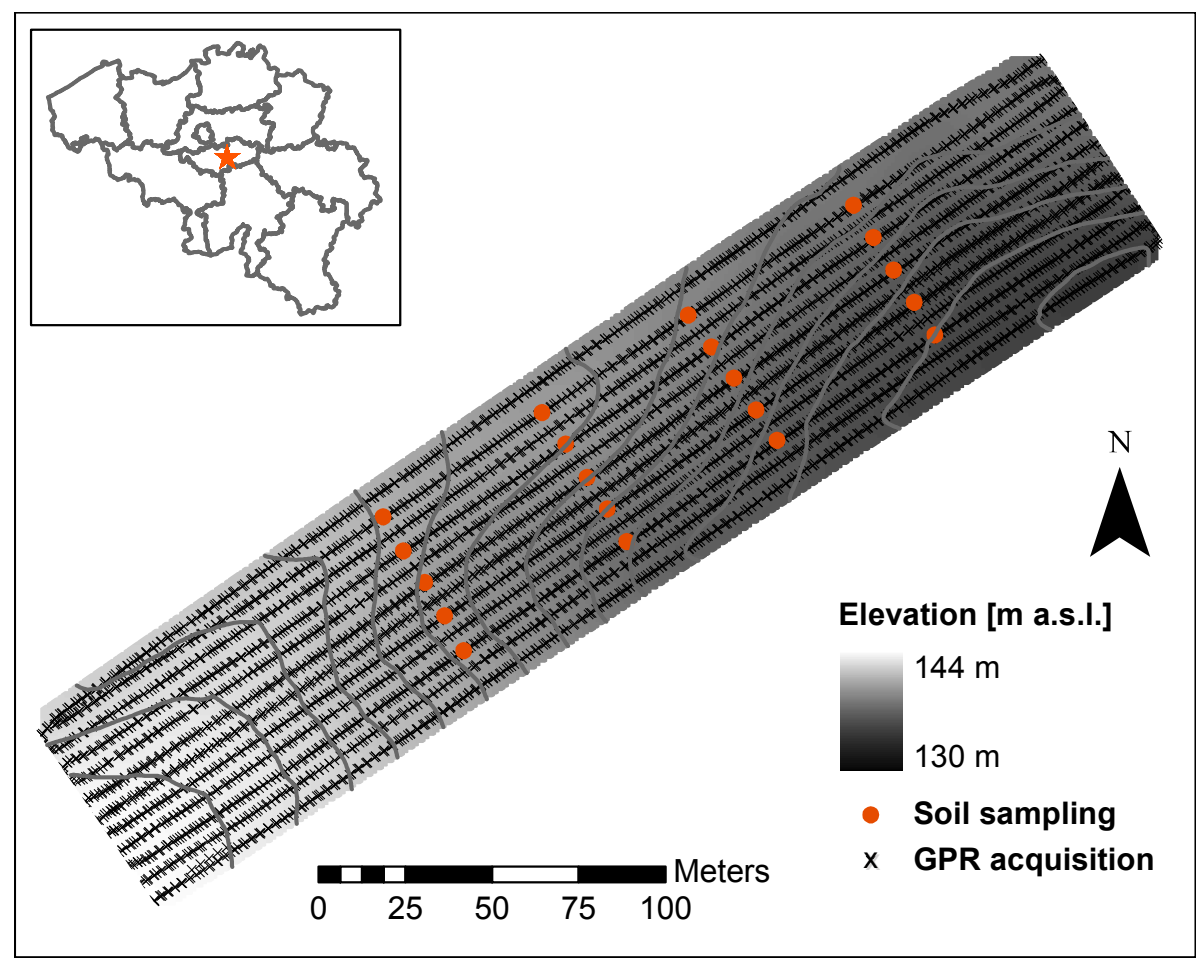

Figure 1: Study site for the GPR acquisition that was performed along 12 parallel lines. Soil core sampling was performed in 20 locations.

441'8’'E, Lat. 50³5'59’'N) (Fig. 1). The soil type is uniformly a silt loam and elevation ranges from 130 to $144 \mathrm{~m}$ a.s.l. According to the national Belgian soil database (Aardewerk, Van Orshoven and Vandenbroucke (1993)), particles fraction are $4 \%$ of sand, $82 \%$ of silt and $14 \%$ of clay for a soil sampling point situated at $500 \mathrm{~m}$ from the field. The GPR acquisition took place at the end of the winter on the $18^{\text {th }}$ of March 2010 in moderately wet conditions. According to a rain gauge station situated 2 $\mathrm{km}$ apart from the field, no rainfall were recorded for 11 days, but evaporation was limited due to low temperatures $\left(3^{\circ} \mathrm{C}\right.$ on average for the 11 previous days). The field was covered by low-grown winter wheat (canopy height lesser than $5 \mathrm{~cm}$ ). Surface roughness was low (amplitude around $5 \mathrm{~cm}$ ) as the field was finely ploughed for wheat sowing four months before the campaign while rainfalls have flattened the soil surface during the winter.

\subsection{Soil moisture sensing by GPR}

\subsubsection{GPR setup}

The GPR principle for soil moisture sensing is based on the propagation of an electromagnetic wave, which is governed, for non-magnetic soils, by the soil dielectric permittivity $\varepsilon$ and electrical conductivity $\sigma$. As the relative dielectric permittivity of wa- ter $\left(\varepsilon_{w} \approx 80\right)$ is much larger than the one of the soil particles $\left(\varepsilon_{s} \approx 5\right)$ and air $\left(\varepsilon_{a}=1\right)$, GPR is mainly sensitive to soil moisture.

The GPR system we used was set up with a vector network analyzer (VNA) (ZVL, Rohde and Schwarz, Münich, Germany) connected to an ultrawideband monostatic horn antenna (BBHA 9120 F, Schwarzbeck Mess-Elektronik, Schönau, Germany) situated off the ground. According to the operating bandwidth of the antenna, the VNA emulated a stepped-frequency electromagnetic wave from 200 to $2000 \mathrm{MHz}$, with a frequency step of $6 \mathrm{MHz}$. For this off-ground configuration, antenna and soil-antenna interactions effects are modeled using frequency-dependent transfer functions for a farfield antenna configuration (Lambot et al., 2006a; Jadoon et al., 2010b).

For field acquisition, we used an all-terrain vehicle (ATV) holding the GPR system, a differential global positioning system (DGPS) (Leica GPS1200, Leica Geosystems) and a PC. The PC automatically integrates the DGPS position, launches GPR measurements and saves all the measured data. Realtime GPR measurements were performed at a regular spacing of two meters along the same track, according to DGPS measurements, which are known with a horizontal precision of about $3 \mathrm{~cm}$. The ATV followed 12 parallel tracks with a spacing of $5 \mathrm{~m}$ 
between the acquisition tracks (see Fig. 1) and a driving speed of about $5 \mathrm{~km} / \mathrm{h}$. The GPR antenna footprint where soil moisture is measured has a diameter of about $1.5 \mathrm{~m}$ and a sampling depth around $5 \mathrm{~cm}$. Three repetitions of the acquisition were performed within $3 \mathrm{~h}$, accounting in total for 4600 measured points. The purpose of the repetitions were to evaluate the reproducibility of the overall GPR technique in field conditions, including the interpolation effect, knowing that the measured points were not taken exactly at the same locations for each repetition but at least were along the same tracks.

\subsubsection{GPR data inversions for surface soil mois- ture}

Surface soil moisture was retrieved using fullwaveform inversion of GPR data focused on the surface reflection. The raw measured GPR data in the frequency domain were first filtered out from the antenna effects using the antenna transfer functions in order to obtain the GPR response from the soil only, as presented in Fig. 2 for an arbitrary GPR measurement. The GPR wave propagation into the soil was modeled using an exact solution of the $3 \mathrm{D}$ Maxwell's equations for waves propagating in a planar layered medium, namely, the Green's function, which simulates the response of the soil illuminated by the GPR antenna, depending on the soil electromagnetic properties. In this study, the soil is considered as a homogeneous medium within the GPR antenna footprint. The reader is referred to Lambot et al. (2004) for a complete explanation of the electromagnetic model.

The frequency-dependent GPR data from field measurements were selected from 200 to $800 \mathrm{MHz}$ as the highest frequencies were affected by measurements noise arising because of soil roughness scattering (Lambot et al., 2006a) (see Fig. 2 (a)). In order to identify the shallow surface soil dielectric permittivity, the GPR data were selected on a time window focused on the soil surface reflection peak, after transformation of GPR data from the frequency to the time domain using the inverse Fourier transform. The soil surface reflection peak can be easily detected as it corresponds to the largest oscillation in the time domain GPR waveform, as delineated in Fig. 2 (b). This time-windowing permitted to identify the surface soil dielectric permittivity and correlated soil moisture from the shallow soil layer (Lambot et al., 2006b; Minet et al., 2011).

Two parameters were optimized in the GPR inversion, namely, the surface soil dielectric permittivity $\varepsilon$ and the GPR antenna height $h_{0}$. The inverse problem was formulated in the least-squares sense and the objective function was accordingly defined as:

$$
\phi(\mathbf{b})=\sqrt{\frac{\mathbf{e}(\mathbf{b})^{T} \mathbf{e}(\mathbf{b})}{n-p}}
$$

with $n$ being the length of the time domain vector, $p$ the number of parameters, and the error function $\mathbf{e}(\mathbf{b})$ defined as the difference between the measured and modeled Green's functions in the time domain with:

$$
\mathbf{e}(\mathbf{b})=\mathbf{g}_{\mathbf{x x}}^{\uparrow *}(t)-\mathbf{g}_{\mathbf{x x}}^{\uparrow}(\mathbf{b}, t)
$$

where $\mathbf{g}_{\mathbf{x x}}^{\uparrow *}(t)$ and $\mathbf{g}_{\mathbf{x x}}^{\uparrow}(\mathbf{b}, t)$ being, respectively, the measured and modeled Green's functions in the time domain $(n \times 1)$ focused on the surface reflection, and $b(p \times 1)$ the parameter vector of the inverse problems $\left(\mathbf{b}=\left[\varepsilon, h_{0}\right]\right)$.

The inverse problem thus consists of finding the minimum of this objective function by optimizing the parameter values. Optimization was performed using a local search algorithm (i.e., the LevenbergMarquardt algorithm (Marquardt, 1963)). The initial guess for the dielectric permittivity was arbitrarily chosen as $\varepsilon=10$ as this was a mean expected value for this parameter (corresponding to a volumetric soil moisture $\theta \approx 0.20 \mathrm{~m}^{3} \mathrm{~m}^{-3}$ ). The initial guess for the GPR antenna height $h_{0}$ was computed for each measured Green's function $\mathbf{g}_{\mathbf{x x}}^{\uparrow *}(t)$ in the time domain using the arrival time of the soil surface reflection peak.

For electrical conductivity lower than $0.01 \mathrm{~S} / \mathrm{m}$, Lambot et al. (2006b) demonstrated that the electromagnetic model was insensitive to the electrical conductivity in a similar frequency range. Therefore, this parameter could be neglected in the optimization and was set to zero in the electromagnetic model. This assumption was nevertheless verified by performing inversions accounting for the optimization of the electrical conductivity, i.e., with $\mathbf{b}=\left[\varepsilon, h_{0}, \sigma\right]$

\subsubsection{Petrophysical relationships}

We used two petrophysical models for relating GPRderived dielectric permittivity $\varepsilon$ to volumetric soil moisture values $\theta$. The first model was the widelyused relationship of Topp et al. (1980) with the classical parameterisation:

$\theta=-5.3 \times 10^{-2}+2.92 \times 10^{-2} \varepsilon-5.5 \times 10^{-4} \varepsilon^{2}+4.3 \times 10^{-6} \varepsilon^{3}$

The Topp's relationship was used to translate the permittivity retrieved by the GPR data inversions into soil moisture. However, the second model, i.e., the model of Ledieu et al. (1986), was used for fitting the GPR-derived permittivity and volumetric soil moisture from soil sampling measurements with: 



(a)

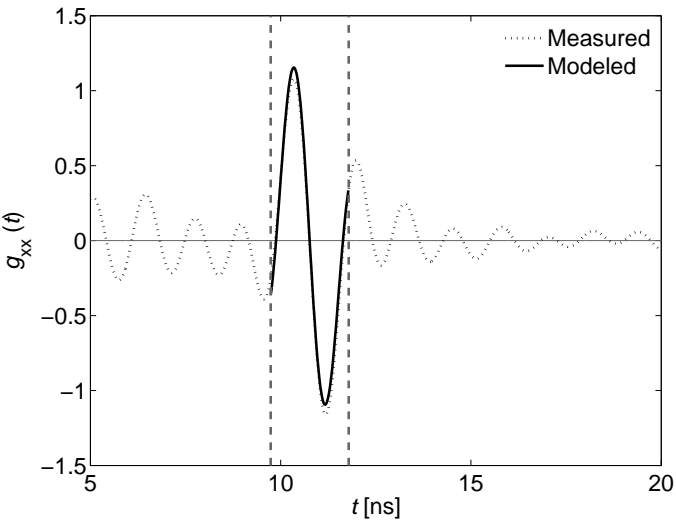

(b)

Figure 2: Measured and modeled Green's function depicted in the frequency domain in amplitude and phase (a) and in time domain (b). The time-window corresponding to the surface reflection is delineated in (b).

$$
\theta=a \sqrt{\varepsilon}+b
$$

where $a$ and $b$ are regression coefficients. This model assumes a linear relationship between $\sqrt{\varepsilon}$ and $\theta$ and appeared to be more robust for fitting the petrophysical relationship over a limited range of soil moisture conditions in this study. It is also worth mentioning that this model is a simplification of physically-based volumetric mixing models (i.e., the complex refractive index model (CRIM) (Birchak et al., 1974; Dobson et al., 1985)).

\subsubsection{Soil moisture interpolation}

Soil moisture maps were produced by the interpolation of point measurements using ordinary kriging. To deal with the uneven disposition of the points in space (i.e., globally a $2 \mathrm{~m}$ spacing along the acquisition line and a $5 \mathrm{~m}$ spacing between lines), a rectangular neighborhood window was chosen such that the same numbers of points were taken in the perpendicular and parallel direction with respect to the acquisition lines direction. Unidirectional variograms were computed and modeled along the acquisition lines using an exponential model accounting for a nugget effect. Interpolated soil moisture values were computed as linear combinations of the values of neighboring points according to the ordinary kriging method.

\subsection{Uncertainties assessment}

Each of the previously exposed steps (i.e., GPR measurements, inversions and interpolation) introduces uncertainties in the final soil moisture maps. In this study, we assess the soil moisture uncertainties by three independent ways:
1. by computing GPR inversion uncertainties according to the modeling error and the model sensitivity to soil moisture;

2. by repeating the acquisition for assessing the reproducibility of the sensing and mapping of soil moisture;

3. by comparing with ground-truth measurements of soil moisture (soil core sampling).

\subsubsection{Inversion uncertainties}

The GPR data inversion consists in finding the optimal set of parameter values that minimizes the objective function (Eq. (1)). The uncertainties of inverted parameters can be quantified from the value of the objective function at its minimum (modeling error) and from its curvature around the minimum (model sensitivity), accounting for GPR measurement and modeling errors. According to Kool and Parker (1988), inverted dielectric permittivity uncertainty $\sigma_{\varepsilon, G P R}$ were determined by the square root of the diagonal element of the parameter variancecovariance matrix $\mathbf{C}(\mathrm{p} \times \mathrm{p})$ corresponding to the dielectric permittivity:

$$
\sigma_{\varepsilon, G P R}=\sqrt{\mathbf{C}_{\varepsilon}}
$$

with the matrix $\mathbf{C}$ being given by:

$$
\mathbf{C}=\frac{\mathbf{e}^{* T} \mathbf{e}^{*}}{n-p}\left(\mathbf{J}^{T} \mathbf{J}\right)^{-1}
$$

where $\mathbf{J}$ is the Jacobian (or sensitivity) matrix ( $\mathrm{n} \times$ p) and $\mathbf{e}^{*}=\mathbf{e}\left(\mathbf{b}^{*}\right)$, the error vector at the minimum of the objective function (see Eq. (2)). The elements $(\mathrm{i}, \mathrm{j})$ of the Jacobian matrix are the partial derivatives 
of the error function $\mathbf{e}(\mathbf{b})$ with respect to the optimized parameters values $\mathbf{b}^{*}$ with:

$$
J_{i, j}=\frac{\delta \mathbf{e}_{\mathbf{i}}}{\delta b_{i}^{*}}
$$

The Jacobian matrix thus reflects the way the model is sensitive to a small parameter change. In practice, the partial derivatives $\frac{\delta \mathbf{e}_{\mathbf{i}}}{\delta b_{i}^{*}}$ of the Jacobian matrix were approximated by finite differences, assuming a change in the parameter value of $1 \%$. The uncertainty in dielectric permittivity $\sigma_{\varepsilon, G P R}$ was translated in uncertainty in soil moisture $\sigma_{\theta, G P R}$ using propagation of error theory:

$$
\sigma_{\theta, G P R}=\frac{\delta \theta(\varepsilon)}{\delta \varepsilon} \sigma_{\varepsilon, G P R}
$$

where $\theta(\varepsilon)$ is the relationship of Topp et al. (1980) (Eq.(3)).

The parameter uncertainty can be seen as the combination of two contributions, that are the modeling error and the parameter insensitivity. The modeling error (or error of fit) is the value of the objective function at its minimum, i.e., the value of the objective function for the optimized parameters $\left(\phi\left(\mathbf{b}^{*}\right)\right)$. The parameter sensitivity is related to the Jacobian matrix, as it expresses the curvature of the objective function in the vicinity of the minimum for a small change in the optimized parameter value. Therefore, the parameter uncertainty is large for a high modeling error and a low parameter sensitivity.

This method assumes that the model is linear in its parameters in the vicinity of the minimum. Although the electromagnetic model is not linear over the full physically-sound parameter range, this assumption may be reasonable when considering a small parameter range. This assumption was successfully verified by performing MarkovChain Monte-Carlo sampling of the parameter space around the minimum of the objective function using the Metropolis-Hastings algorithm implemented in the differential evolution adaptive metropolis (DREAM) algorithm (Vrugt et al., 2009). For nonlinear problems, this algorithm can efficiently draw the complete posterior parameter distributions.

\subsubsection{Repetition uncertainties}

The three repetitions were compared one by one by mapping the difference of the interpolated soil moisture values $\Delta \theta$. The comparison had to be done based on interpolated values because the GPR measurements could not be taken strictly at the same locations, although the same acquisition tracks were followed for each repetition. The global repetition error was computed as the root mean square of the differences between the repetitions $\left(\mathrm{RMSE}_{r e p}\right)$.
Moreover, in order to truly compare the repetitions, the effect of the interpolation (kriging) was taken into account for comparing the maps of the difference between these repetitions. If the soil moisture is assumed as time-invariant for all repetitions, the part of the repetition uncertainty that is due to the interpolation of two datasets with different point locations can be assessed by the variance of the difference in the interpolated values $\sigma_{\Delta \theta}^{2}$, which was estimated in each point of the interpolated space $x_{0}$ as:

$\sigma_{\Delta \theta}^{2}\left(x_{0}\right)=\sigma_{\theta_{1}}^{2}\left(x_{0}\right)+\sigma_{\theta_{2}}^{2}\left(x_{0}\right)-2 \mathbf{w}_{\theta_{\mathbf{1}}}^{\mathbf{T}} \mathbf{K}_{\theta_{1}, \theta_{\mathbf{2}}} \mathbf{w}_{\theta_{\mathbf{2}}}$

where $\sigma_{\theta_{1}}^{2}\left(x_{0}\right)$ and $\sigma_{\theta_{2}}^{2}\left(x_{0}\right)$ are the variance of the kriging predictor for the first and second repetitions, respectively, $\mathbf{w}_{\theta_{1}}$ and $\mathbf{w}_{\theta_{2}}$ are the weights of the kriging predictor for the first and second repetitions, respectively, and $\mathbf{K}_{\theta_{1}, \theta_{2}}$ is the covariance matrix between the points of the first and second repetitions. This variance $\sigma_{\Delta \theta}^{2}$ is the uncertainty on the predicted value given the fact that two sets of sampling locations are used for estimating soil moisture at the same location $x_{0}$. For each interpolated point, this variance depends only on the relative locations of the measured points of both repetitions, meaning that a null variance would be obtained if the points of two repetitions were exactly located at the same locations.

A standardized difference of the interpolated soil moisture $\Delta \theta^{*}$ can be computed by:

$$
\Delta \theta^{*}=\frac{\Delta \theta}{\sqrt{\sigma_{\Delta \theta}^{2}}}
$$

where $\Delta \theta^{*}$ is following the standard normal distribution $(\sim \mathrm{N}(0,1))$. By computing this standardized variable, the significance of the observed difference in interpolated soil moisture can easily be computed and errors can be compared over space independently of the interpolation effect.

\subsubsection{Comparison with soil sampling measure- ments}

In order to validate the accuracy of the GPR soil moisture measurements, surface soil moisture was independently measured by volumetric soil core sampling in the top $5 \mathrm{~cm}$ at 20 regularly spaced locations (see Fig. 1). Soil samples were oven-dried at $105^{\circ} \mathrm{C}$ for at least $48 \mathrm{~h}$ and the dry and wet weights were measured, in order to determine the volumetric moisture. The volumetric soil moisture of the soil samples was then compared with the interpolated value of the GPR-derived dielectric permittivity using the three repetitions for the interpolation at the locations of the soil core sampling. 

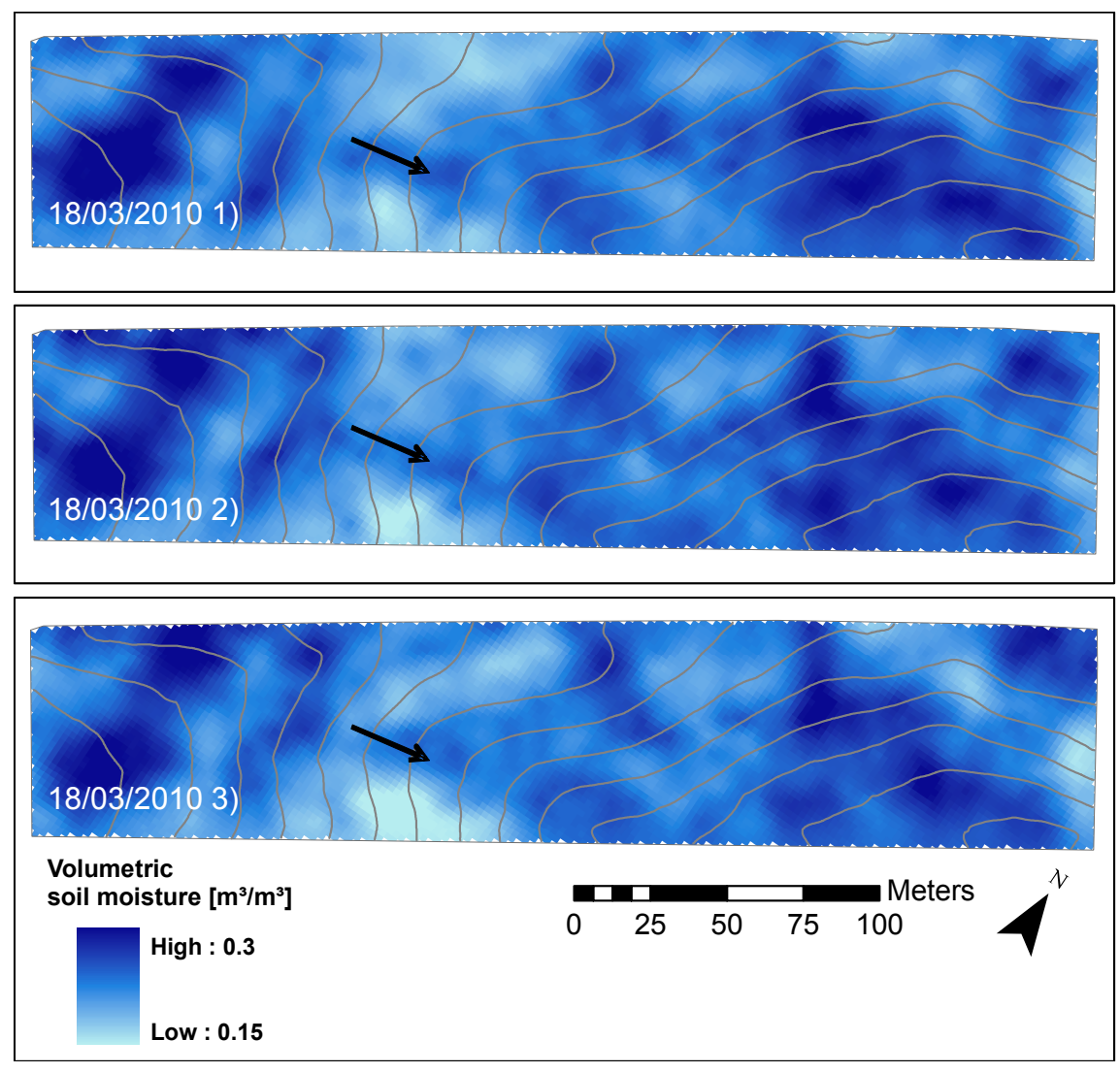

Figure 3: Soil moisture maps for the three acquisitions. Topographic contour lines with an interdistance of one meter are depicted in grey lines. The black arrows indicate the location and the direction of the slope of the main thalweg in the field. 


\section{Results}

\subsection{Surface soil moisture maps}

Figure 3 presents the interpolated soil moisture maps from the three GPR acquisitions. Soil moisture pattern was driven by topography, as the soil and vegetation conditions were rather homogeneous. High soil moisture values were encountered in the lowest and highest elevated parts of the field, respectively, at the right and left of the figure, where the field is actually quite flat. The center of the thalweg, indicated with an arrow on the maps, appeared wetter than its surroundings. The field-average soil moisture was equal to about $0.23 \mathrm{~m}^{3} \mathrm{~m}^{-3}$ with a standard deviation of $0.06 \mathrm{~m}^{3} \mathrm{~m}^{-3}$, with very similar values between the three repetitions (see Table 1). When optimizing the electrical conductivity in the GPR inversions, negligible impact was observed on the optimization of the permittivity $\varepsilon$ (mean absolute error of 0.059 in terms of $\varepsilon$ comparing to GPR inversions without the optimization of the electrical conductivity).

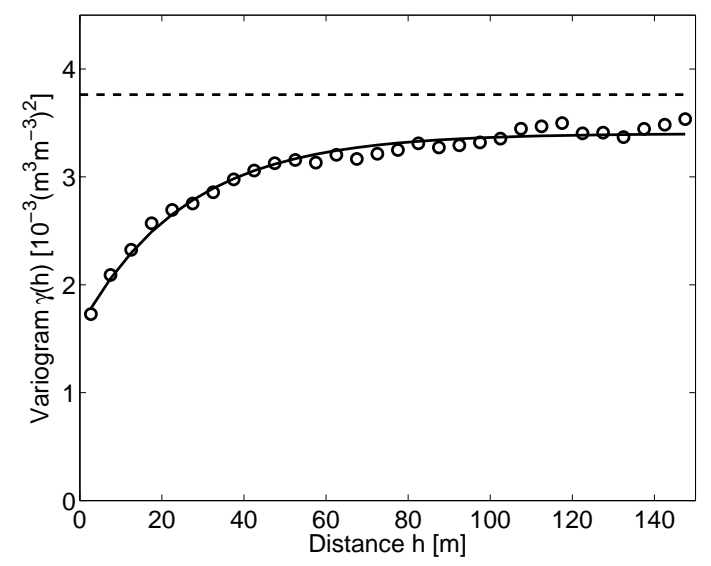

Figure 4: Variogram for soil moisture computed along the acquisition lines for the three repetitions. An exponential model is fitted on the variogram estimates. The sampling variance is indicated by the horizontal dashed line.

The observed soil moisture exhibited a very similar spatial correlation between the three repetitions, so that a unique variogram was used for interpolating the soil moisture point measurements (Fig. 4). An exponential model was fitted over the variogram estimates (nugget $=1.6010^{-3}\left(\mathrm{~m}^{3} \mathrm{~m}^{-3}\right)^{2}$, partial sill $=1.8010^{-3}\left(\mathrm{~m}^{3} \mathrm{~m}^{-3}\right)^{2}$, range $\left.=77 \mathrm{~m}\right)$.

\subsection{Inversion uncertainties}

Inverted parameter uncertainties are affected by both modeling error and model sensitivity to the param- eters (see Eq. (6)). Figure 5 shows the maps of the interpolated modeling error for the three repetitions. The modeling errors appeared to be spatially and temporally correlated. The spatial correlation was moderate, with nugget/sill ratios of $0.66,0.66$ and 0.49 , for the three repetitions, respectively. However, the coefficients of correlation between the three repetitions ranged from 0.81 to 0.87 , indicating large temporal correlations, as it could be expected from a visual comparison of the three maps. In particular, a patch of the field, situated in the middle left along the bottom limit of the field, was affected by a very high modeling error compared to the rest of the field. Furthermore, the location and the shape of the patch remained identical between the three repetitions.

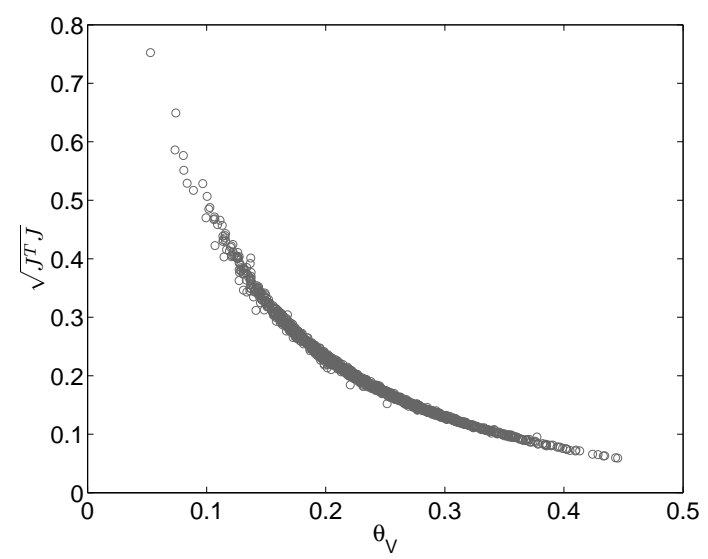

Figure 6: Observed sensitivity of the electromagnetic model, expressed by the sum of the elements of the Jacobian matrix for the permittivity, as a function of inverted soil moisture.

Figure 6 presents the observed model sensitivity to the permittivity, i.e., the sum of the elements of the Jacobian matrix for the permittivity, as a function of inverted soil moisture for the first repetition. The sensitivity of the electromagnetic model to the dielectric permittivity was decreasing with increasing soil moisture. It indicated that for high soil moisture, a large variation of soil moisture results in a small variation of the model response. It is worth mentioning that the sensitivity is presented here as a function of soil moisture, instead of soil dielectric permittivity. Nevertheless, the relationship between dielectric permittivities and model sensitivity appeared similar, although more curved.

Figure 7 presents the maps of the interpolated soil moisture uncertainty $\sigma_{\theta, G P R}$ for the three repetitions. The soil moisture uncertainties appeared very small, with a mean equal to $0.0039 \mathrm{~m}^{3} \mathrm{~m}^{-3}$ for the three repetitions. As well as for the modeling error maps (Fig. 5), soil moisture uncertainties appeared temporally and spatially correlated. The 
Table 1: Statistics of GPR-derived volumetric soil moisture $\left[\mathrm{m}^{3} \mathrm{~m}^{-3}\right]$ (non-interpolated values)

\begin{tabular}{cccccc}
\hline Repetition & $\mu_{\theta}$ & $\operatorname{median}_{\theta}$ & $\sigma_{\theta}$ & $\theta_{\min }$ & $\theta_{\max }$ \\
\hline 1 & 0.234 & 0.227 & 0.063 & 0.053 & 0.445 \\
2 & 0.236 & 0.232 & 0.061 & 0.054 & 0.456 \\
3 & 0.233 & 0.230 & 0.063 & 0.051 & 0.436 \\
\hline
\end{tabular}
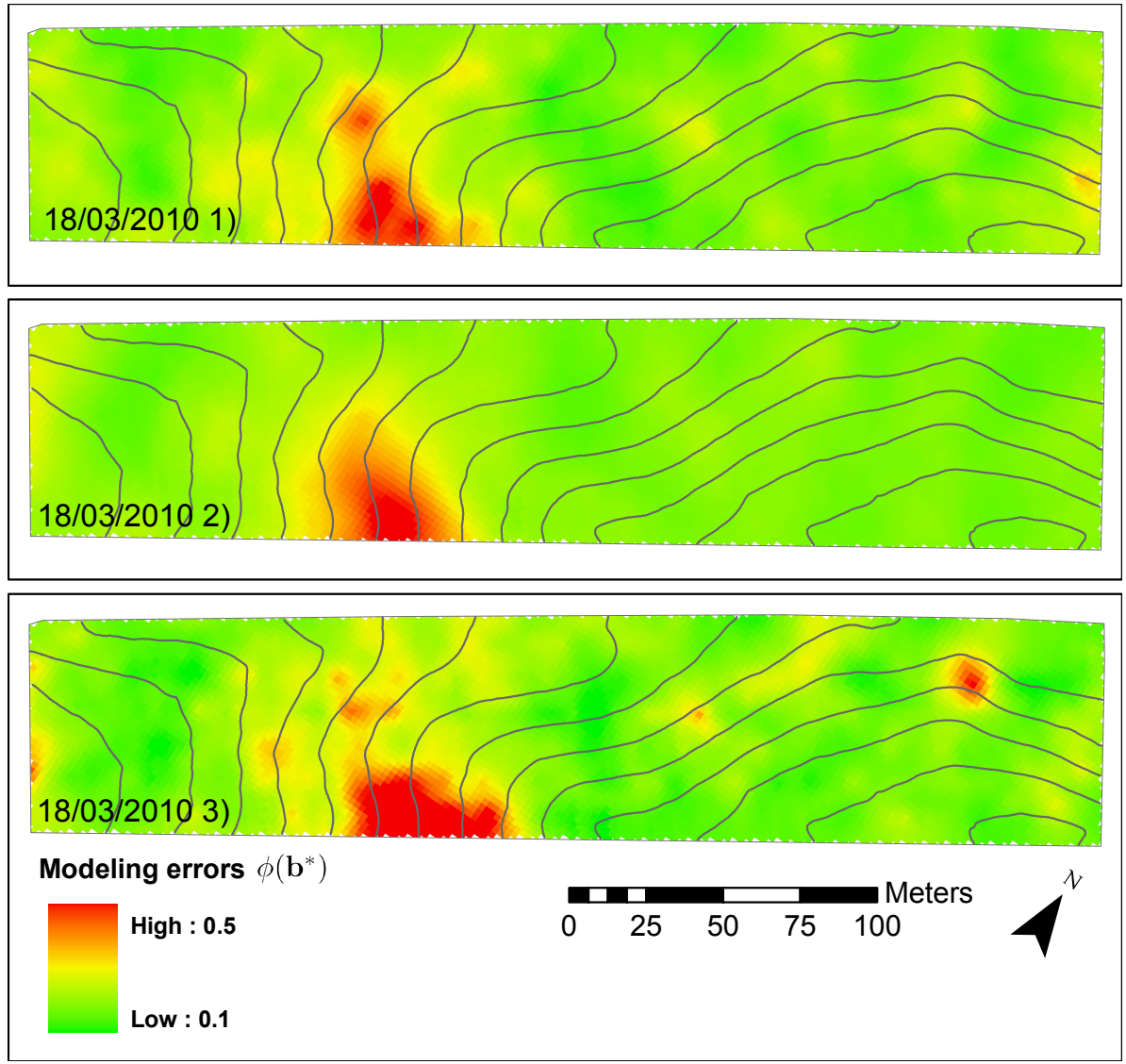

Figure 5: Maps of the interpolated modeling error $\phi\left(\mathbf{b}^{*}\right)$. Topographic contour lines with an interdistance of one meter are depicted in grey lines. 

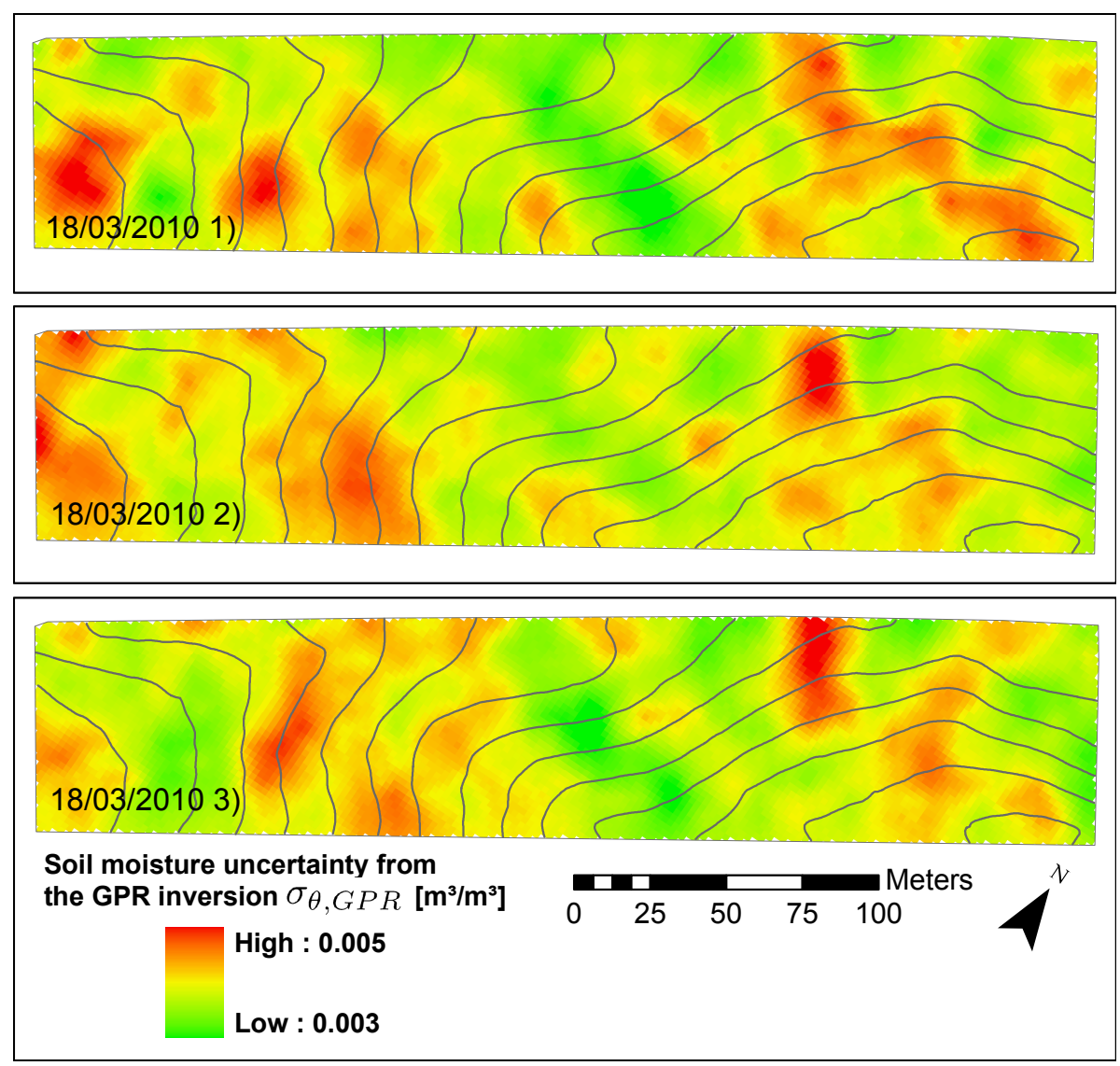

Figure 7: Maps of the soil moisture uncertainty $\sigma_{\theta, G P R}$ computed using Eqs (5) to (8). Topographic contour lines with an interdistance of one meter are depicted in grey lines. 
$\sigma_{\theta, G P R}$ pattern (Fig. 7) resulted from the combination of the modeling errors (Fig. 5) and the soil moisture sensitivity, which is inversely related to the soil moisture pattern (Fig. 3). As the relationship between soil moisture and model sensitivity to the permittivity is clearly defined (see Fig. 6), the soil moisture uncertainty maps is inversely related with the soil moisture pattern, with a coefficient of correlation of 0.403 between $\theta$ and $\sigma_{\theta, G P R}$ for the noninterpolated values. When optimizing the electrical conductivity in the GPR inversions, the uncertainties in $\varepsilon$ were poorly affected (mean absolute error of 0.038 in terms of $\varepsilon$ ). The uncertainties in electrical conductivity were however abnormally high with values outside of the realistic physical range for soils, as a result of the poor sensitivity of this parameter to the model in that frequency range and for low conductive conditions.

The assumption of linearity of the electromagnetic model to its parameters was asserted by performing Markov-Chain Monte-Carlo sampling of the parameter space. The standard deviations of the complete posterior distributions of the optimized parameter and the uncertainties computed using the method of Kool and Parker (1988) appeared remarkably similar (results not shown). The use of a Markov-Chain Monte-Carlo sampling is therefore unnecessary, knowing that it requires about 1000 times more computation time.

\subsection{Repetition uncertainties}

The interpolated soil moisture maps (Fig. 3) showed very similar patterns when comparing the three repetitions, with coefficients of correlation of 0.87 between the first and second repetitions, 0.88 between the second and third repetitions and 0.81 between the first and third repetitions. Figure 8 shows the repetition uncertainty maps (i.e, the difference in interpolated soil moisture of each repetition to each other $\Delta \theta$ ) between the three repetitions. The global repetition errors $\mathrm{RMSE}_{r e p}$ were found to be equal to $0.0164,0.0156$ and $0.0186 \mathrm{~m}^{3} \mathrm{~m}^{-3}$ for the three maps, respectively. The repetition uncertainty patterns were poorly spatially correlated, although some parts of the field exhibited small patches of similar repetition uncertainties. Some similitude could be observed with the modeling error maps (Fig. 5). In particular, the patch of high modeling error in the middle left along the bottom limit of the field corresponded here to larger repetition errors than the rest of the field.

A part of the observed differences $\Delta \theta$ can be attributed to the effect of the interpolation, knowing that different sets of measurements were used for interpolating at same locations. The field-averaged deviations of the difference between the repetitions $\sigma_{\Delta \theta}$ computed by Eq. (9) were found to be equal to $0.0143,0.0141$ and $0.0143 \mathrm{~m}^{3} \mathrm{~m}^{-3}$ for the three maps shown in Fig. 8, respectively, denoting that the interpolation effect accounted for a large part in the observed discrepancies between repetitions. The zones delineated in Fig. 8 with black lines highlight the places where the standardized difference of the interpolated soil moisture $\Delta \theta^{*}$ (see Eq. (10)) is outside of the range $[-2,2]$, i.e., the zones where the two repetitions of the acquisition resulted in different soil moisture estimates at $95 \%$ of confidence level, independently of the interpolation effect. These zones were rather small and appeared randomly located in the field. Finally, it is worth noting that the difference between the first and third repetition was larger than between the other repetitions, i.e., the $\mathrm{RMSE}_{r e p 1,3}$ was the largest and the zones of different soil moisture estimates were the most extended. This could indicate a real change in soil moisture as the elapsed time between the first and third repetitions was the largest (two hours instead of one hour).

\subsection{Comparison with soil sampling measurements}

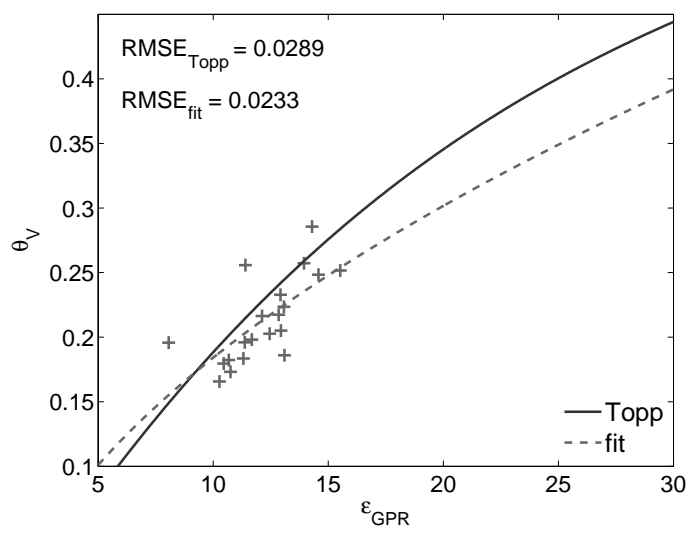

Figure 9: Comparison between interpolated GPRderived soil dielectric permittivity $\varepsilon_{G P R}$ and volumetric sampling soil moisture $\theta_{V}$.

Figure 9 presents the comparison between interpolated GPR-derived soil dielectric permittivity $\varepsilon_{G P R}$ using the three repetitions and volumetric soil moisture $\theta_{V}$ from the soil sampling measurements. A simple petrophysical (Ledieu et al., 1986) (Eq. (4)) was fitted over the data and the standard relationship of Topp et al. (1980) (Eq. (3)) was also drawn for comparison. There was a good agreement between the soil permittivity and moisture, with a $\mathrm{RMSE}_{\text {fit }}$ of $0.0233 \mathrm{~m}^{3} \mathrm{~m}^{-3}$ when fitting the Ledieu's model, as well as when comparing 

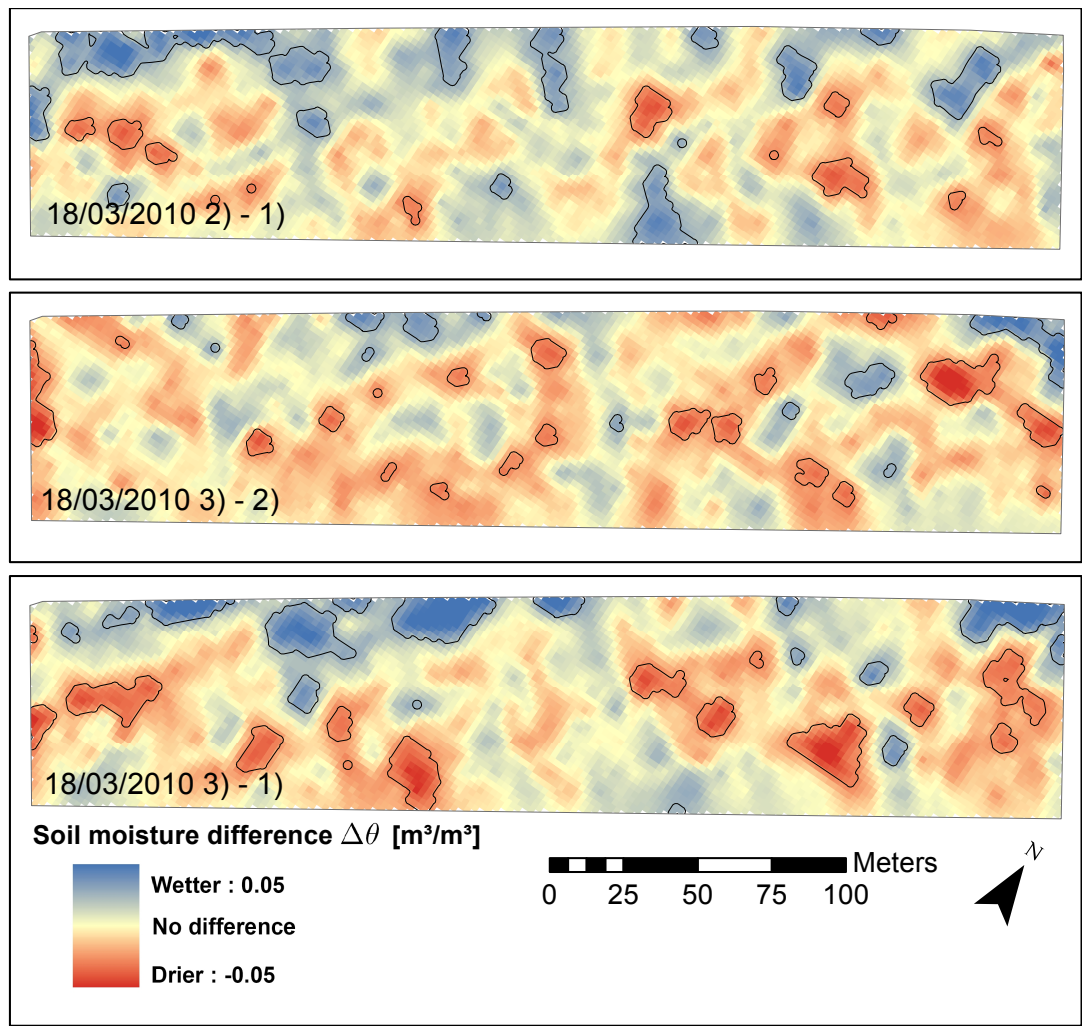

Figure 8: Maps of the repetition uncertainties for the three acquisitions. The repetition uncertainty is computed as the difference between the interpolated values of each repetitions. The black lines delineated the zones where the two repetitions of the acquisition resulted in different soil moisture estimates, at $95 \%$ of confidence. 
with the Topp's relationship $\left(\mathrm{RMSE}_{\text {Topp }}=0.0289\right.$ $\left.\mathrm{m}^{3} \mathrm{~m}^{-3}\right)$. The Topp's and fitted relationships were therefore in good agreement, except for high soil moisture. When considering the three repetitions for interpolating the GPR-derived permittivity separately, $\mathrm{RMSE}_{\text {fit }}$ were equal to $0.0222,0.0216$ and $0.0259 \mathrm{~m}^{3} \mathrm{~m}^{-3}$ for the three repetitions, respectively (Table 2).

\section{Discussions}

\subsection{Inversion uncertainties}

The GPR-derived soil moisture uncertainties thus resulted from the combination of the modeling error and the soil moisture sensitivity. The decreasing model sensitivity with increasing soil moisture is related to the non-linearity of the Fresnel reflection coefficient function with the soil dielectric permittivity for an air/soil interface. The non-linearity of the petrophysical model relating the soil permittivity to the soil moisture reduces the degree of this nonlinearity, but not to a sufficient extent. However, it is worth noting that for TDR and GPR methods that are based on the determination of the travel time of the wave propagation rather than on the surface reflection coefficient, the relationship between the soil moisture and the travel time is linear, assuming a Ledieu's like petrophysical relationship (Herkelrath et al., 1991; Huisman et al., 2001).

Non-null modeling errors indicated model inadequacies, i.e., the soil differed from the homogeneous medium it was supposed to be. The large spatial and temporal correlation and the similar patterns observed in the modeling error maps (Fig. 5) and, to a lesser extent, in the other uncertainty maps (Fig. 7 and 8), denoted that model inadequacies were probably related to local soil conditions, especially because modeling errors appeared to be spatially correlated when considering adjacent acquisition tracks. The model inadequacies caused a large modeling error (Fig. 5), that, in turn may impair the capacity of the GPR to sense the same soil moisture at each repetition (Fig. 8). As the errors appeared strongly dependent on local conditions rather than being randomly distributed or time-dependent, this therefore discarded the hypothesis of errors caused by a sensor drift, vibrations of the platform, or any measurement problems that are not linked to local soil conditions.

High electrical conductivity, surface soil roughness and within-support heterogeneities were identified as the hypothetic model inadequacies and were discussed below. First, highly conductive soils conditions may impact on the retrieval of the dielectric permittivity in the GPR inversion if not well accounted for (Giroux and Chouteau, 2010). Never- theless, in our study, optimizing the electrical conductivity in the GPR inversions did not impact on the retrieval of dielectric permittivities nor on the inversion uncertainties of dielectric permittivities. The huge uncertainties in electrical conductivity denoted a complete insensitivity of this parameter to the electromagnetic model, as already observed in Lambot et al. (2006b) for conductivity values lower than 0.01 $\mathrm{S} / \mathrm{m}$, using the same GPR system and a similar frequency bandwidth (i.e., 100-900 MHz). As a result, GPR inversions neglecting the optimization of the electrical conductivity were used in this study.

Second, large surface soil roughness may impact on the reflection of the GPR wave by causing interferences. Using the same GPR setup, the effect of surface roughness on the retrieval of the dielectric permittivity was analyzed in laboratory in Lambot et al. (2006a) and widely discussed in case of field acquisition in Minet et al. (2011). Owing to the relatively low-frequency range used in the GPR inversion, surface soil roughness may significantly impact only for roughness larger than $5 \mathrm{~cm}$. From visual field observation, we can state that such rough conditions were not widely encountered.

Lastly, lateral and vertical soil moisture heterogeneities within the GPR antenna footprint, which is assumed to be an homogeneous medium, could be an important cause of model inadequacy. The effect of vertically-varying soil moisture was investigated through numerical and laboratory experiments in Minet et al. (2010a) and in field conditions in Minet et al. (2011). In the presence of a shallow soil layer of a different moisture content than the sublayer, a RMSE of $0.05 \mathrm{~m}^{3} \mathrm{~m}^{-3}$ in the soil moisture estimation was obtained (Minet et al., 2010a, laboratory experiment). For small contrast between the layers $(<0.05)$, the error was nevertheless negligible. The presence of a vertically-varying soil moisture profile can be detected in measured Green's functions over a large frequency bandwidth. Nevertheless, in this study, such conditions could not be revealed through an analysis of the Green's functions. The absence of observed profile conditions in the GPR data could originate from a poorly developed soil moisture profile (i.e., small contrast between surface and subsurface) or from a profile that is too deep to be sensed, with respect to the relatively small penetration depth of the GPR. In addition, no differences in the shape of the measured Green's functions could be observed when comparing GPR data from the zones where low and high uncertainties were identified with the different methods. This did not support the use of multi-layered medium inversions, as it would furthermore increase the inversion uncertainties for the optimized parameters. 


\subsection{Repetition uncertainties}

A large part of the repetition uncertainties was explained by interpolation effects, given that different point measurements were used for each repetition. This could be related to the small-scale spatial variability of soil moisture and the relatively large nugget effect observed in the variogram. It is worth mentioning that this variance of the difference increases with the spacing between point measurements of two repetitions.

The residual repetition uncertainties that were not explained by the interpolation process may indicate either a real change in soil moisture or a different sensing of soil moisture by the GPR. The slightly larger difference between the first and third repetitions seemed to indicate a real change that could originate from surface evaporation or a slight soil compaction caused by the ATV, although these processes could not be explicitly proved.

Using cross-boreholes GPR measurements, Alumbaugh et al. (2002) found a repeatability error of $0.54 \mathrm{~ns}$ in the ground wave velocity, corresponding to a soil moisture error of about 0.005 $\mathrm{m}^{3} \mathrm{~m}^{-3}$. Errors were increasing with soil moisture and were attributed to instrument instability. When comparing repeated CMP surface measurements, Jacob and Hermance (2004) found a precision of $0.7 \mathrm{~ns}$ in the two-way travel time. Huisman and Bouten (2003) reached a reproducibility of 0.003 $\mathrm{m}^{3} \mathrm{~m}^{-3}$ when using single trace analysis of GPR ground wave data for soil moisture determination. In these studies, no uncertainties due to the interpolation and small-scale variability were taking part, which are however determinant for the repetitions uncertainties in our study.

\subsection{Comparison with soil sampling measurements}

The high accuracy of the GPR method for soil moisture sensing was established from the comparison with soil sampling measurements. The use of the Topp's relationship was also validated. However, the small range of permittivity values did not permit to verify this agreement over the full physical range of soil moisture. The observed discrepancies can be attributed to the different support scales and depths of characterization of the techniques, with respect to the important small-scale variability of soil moisture. Spatially-varying soil properties makes the use of a unique petrophysical model for the whole field questionable as well. In addition, soil moisture values from the soil sampling points were compared with interpolated dielectric permittivity, as both measurements were not taken exactly at the same locations, at least in the same acquisition line. Therefore, interpolation uncertainties can explain a large part of the observed discrepancies. Lastly, soil moisture values from sampling measurements can be affected by measurements errors as well.

The comparison of the GPR estimates with soil sampling measurements or other invasive measurements in field conditions is actually problematic because of the different support scales of the techniques. Using the same off-ground GPR in field conditions, Jadoon et al. (2010a) found a RMSE of $0.025 \mathrm{~m}^{3} \mathrm{~m}^{-3}$ between TDR and GPR estimates, but a soil moisture variability of 0.02 to $0.07 \mathrm{~m}^{3} \mathrm{~m}^{-3}$ was measured by TDR within each GPR footprint. Therefore, knowing this important submetric variability, it is problematic to compare a soil core sample (3 cm diameter) with the GPR antenna footprint $(\sim 1.5 \mathrm{~m}$ diameter). With respect to the depths of penetration, Jadoon et al. (2010a) found that the GPR waves may sense the soil moisture up to $4 \mathrm{~cm}$ depth (which was close to the sampling depth of the core $(5 \mathrm{~cm}))$ but it is worth noting that this depth actually varies depending on the soil moisture itself.

Considering the whole field, the use of a unique petrophysical relationship may be affected by some limitations as this relationship may depend on the specific local soil conditions (e.g., soil texture, porosity). In addition, the use of different petrophysical models, even when calibrated with field data, can result in differences in terms of volumetric soil moisture up to $0.10 \mathrm{~m}^{3} \mathrm{~m}^{-3}$ (Sambuelli, 2009; Steelman and Endres, 2010). Despite these important limitations, the comparison with soil sampling measurements is still the only method for quantifying the accuracy of the GPR method, in addition to its precision.

\subsection{Comparison of the uncertainties}

In this section, we discuss the global soil moisture uncertainties quantified by the different methods and averaged over the whole field (Table 2). The two first uncertainties assessment methods, i.e., inversion and repetition uncertainties, evaluated the precision of the GPR technique while the comparison with ground-truth of soil moisture also evaluated its accuracy. The lowest uncertainties were the GPR inversion uncertainties $\sigma_{\theta, G P R}$, which were derived from GPR inversions only, i.e., without influence of the interpolation effects. It is however unknown to what extent this represented the total uncertainty associated with a GPR measurement.

The global repetition errors $\mathrm{RMSE}_{r e p}$ could be assumed to result from the combination of the point measurement uncertainty and the uncertainty associated with the interpolation. It can be noticed that, 
Table 2: Summary of the soil moisture uncertainties $\left[\mathrm{m}^{3} \mathrm{~m}^{-3}\right]$ determined by the different methods

\begin{tabular}{lcc}
\hline & GPR inversion uncertainties $\left(\sigma_{\theta, G P R}\right)$ & Comparison with soil sampling $\left(\mathrm{RMSE}_{f i t}\right)$ \\
Repetition 1 & 0.00392 & 0.0222 \\
Repetition 2 & 0.00398 & 0.0216 \\
Repetition 3 & 0.00394 & 0.0259 \\
All & 0.0039 & 0.0233 \\
\hline & Repetition uncertainties $\left(\mathrm{RMSE}_{r e p}\right)$ & Deviation of the difference $\left(\sigma_{\Delta \theta}\right)$ \\
Repetition 1 vs 2 & 0.0164 & 0.0143 \\
Repetition 2 vs 3 & 0.0156 & 0.0141 \\
Repetition 1 vs 3 & 0.0186 & 0.0143 \\
All & 0.0169 & 0.0142 \\
\hline
\end{tabular}

globally, the values of the $\mathrm{RMSE}_{r e p}$ appeared to be close to the sum of the mean GPR inversion uncertainties $\sigma_{\theta, G P R}$ and of the deviation of the difference in the interpolated values $\sigma_{\Delta \theta}$, this latter accounting for the major part of the repetition error. Nevertheless, locally, the repetition uncertainty could not be seen as simply the sum of $\sigma_{\theta, G P R}$ and $\sigma_{\Delta \theta}$, as it can be verified by a close examination of Figs. 7 and 8. In addition, repetition uncertainties might be also influenced by a real change of soil moisture, which could not be quantified given its expected minor changes.

The largest uncertainty was found when comparing the interpolated GPR-derived permittivity to the soil moisture sampling measurements (Fig. 9), as this inherently combined the uncertainty from the GPR measurement and inversion, the interpolation of soil moisture and the reliability of the petrophysical relationship $\theta-\varepsilon$. Nevertheless, these uncertainties remained weak as compared to previous studies and with respect to the range of soil moisture measured in the field $\left(\sim 0.15 \mathrm{~m}^{3} \mathrm{~m}^{-3}\right)$.

The nugget effect, corresponding to a deviation of $0.0400 \mathrm{~m}^{3} \mathrm{~m}^{-3}$, was assumed to reflect the combined effect of the small-scale variability of soil moisture and the measurement uncertainty. However, this nugget effect appeared to be larger than the uncertainties in soil moisture determined in this study. This is an important finding with respect to the sampling strategies when measuring soil moisture with the proposed GPR method. It is particularly encouraging that the uncertainty in soil moisture measured by GPR appeared lower than the soil moisture variability at the support and resolution scales of the GPR acquisition.

\section{Conclusions and perspectives}

We evaluated the uncertainties in surface soil moisture sensing and mapping of a 2,5 ha agricultural field by full-waveform inversion of GPR data in a comprehensive manner by three independent uncertainty assessment methods.

1. The global uncertainty from the GPR inversion, that is, the point measurement uncertainty, was very low, i.e, $0.0039 \mathrm{~m}^{3} \mathrm{~m}^{-3}$. Locally, this uncertainty was large for high soil moisture values (lower sensitivity) and for high modeling errors.

2. The global repetition error was found to be equal to $0.0169 \mathrm{~m}^{3} \mathrm{~m}^{-3}$ and was largely attributed to the interpolation effect.

3. The accuracy of the GPR method was evaluated by the comparison with soil sampling measurements (ground-truth) and resulted in a RMSE of $0.0233 \mathrm{~m}^{3} \mathrm{~m}^{-3}$, mainly due to the different support scales of the techniques.

The soil moisture sensing by the GPR system thus appeared to be very precise, reproducible and in a good agreement with ground-truthing. The three independent uncertainty assessment methods permitted to investigate the different sources of errors in soil moisture mapping and the interpolation appeared to be an important source of uncertainty. Furthermore, the uncertainties were mapped and local spots of high uncertainty were discussed. The temporal and spatial correlation of the uncertainties seemed to indicate that a part of the uncertainties originated from local model inadequacies, but these latter could not be clearly identified nor accounted for.

The evaluated GPR method for soil moisture sensing and mapping shows very promising potentialities for measuring the soil moisture at an intermediate scale between the remote sensing platforms and invasive sensors. Potential applications are the validation of remote sensing products, the analysis of the temporal stability of soil moisture patterns and other hydrology-related applications. In particular, the high spatial resolution of the GPR acquisitions may be combined with the high temporal resolution 
of grounded sensors network for an unprecedented spatiotemporal characterization of soil moisture patterns.

\section{Acknowledgements}

We acknowledge Guido Rentmeesters for the GPR platform construction. The research presented in this paper was funded by the Belgian Science Policy Office in the frame of the Stereo II programme - project SR/00/100 (HYDRASENS), the DIGISOIL project financed by the European Commission under the 7th Framework Programme for Research and Technological Development, Area "Environment", Activity 6.3 "Environmental Technologies" and the Fonds de la Recherche Scientifique (FNRS), Belgium.

\section{References}

Alumbaugh, D., Chang, P., Paprocki, L., Brainard, J., Glass, R. J., Rautman, C. A., 2002. Estimating moisture contents in the vadose zone using crossborehole ground penetrating radar: A study of accuracy and repeatability. Water Resources Research 38, 1309.

Benedetto, A., 2010. Water content evaluation in unsaturated soil using GPR signal analysis in the frequency domain. Journal of Applied Geophysics 71 (1), 26-35.

Bikowski, J., van der Kruk, J., Huisman, J. A., Vereecken, H., Vrugt, J. A., 2010. Inversion and sensitivity analysis of GPR data with waveguide dispersion using Markov Chain Monte Carlo simulation. In: Proceedings of the XIII International Conference on Ground Penetrating Radar. Lecce (Italy), 21-25 June 2010, pp. 722-726.

Birchak, J. R., Gardner, C. G., Hipp, J. E., Victor, J. M., 1974. High dielectric constant microwave probes for sensing soil moisture. Proc. IEEE 62, 93-102.

Bogena, H., Herbst, M., Huisman, J., Rosenbaum, U., Weuthen, A., Vereecken, H., 2010. Potential of Wireless Sensor Networks for Measuring Soil Water Content Variability. Vadose Zone Journal 9, 1002-1013.

Chanzy, A., Tarussov, A., Judge, A., Bonn, F. 1996. Soil water content determination using digital ground penetrating radar. Soil Science Society of America Journal 60, 1318-1326.
Dobson, M. C., Ulaby, F. F., Hallikainen, M. T., ElRayes, M. A., 1985. Microwave dielectric behavior of wet soil - Part II: Dielectric mixing models. IEEE Transactions on Geoscience and Remote Sensing 23, 35-46.

Galagedara, L. W., Parkin, G. W., Redman, J. D., P., Endres, A. L., 2005. Field studies of the GPR ground wave method for estimating soil water content during irrigation and drainage. Journal of Hydrology 301, 182-197.

Giroux, B., Chouteau, M., 2010. Quantitative analysis of water-content estimation errors using ground-penetrating radar data and a low-loss approximation. Geophysics 75 (4), WA241-WA249.

Grote, K., Anger, C., Kelly, B., Hubbard, S., Rubin, Y., 2010. Characterization of Soil Water Content Variability and Soil Texture using GPR Groundwave Techniques. Journal of Environmental and Engineering Geophysics 15 (3, Sp. Iss. SI), 93110.

Grote, K., Hubbard, S. S., Rubin, Y., 2003. Fieldscale estimation of volumetric water content using GPR ground wave techniques. Water Resources Research 39(11), 1321.

Herkelrath, W. N., Hamburg, S. P., Murphy, F., 1991. Automatic, real-time monitoring of soil moisture in a remote field area with time domain reflectometry. Water Resources Research 27 (5), 857-864.

Huisman, J. A., Bouten, W., 2003. Accuracy and reproducibility of measuring soil water content with the ground wave of ground-penetrating radar. Journal of Environmental and Engineering Geophysics 8(2), 65-73.

Huisman, J. A., Hubbard, S. S., Redman, J. D., Annan, A. P., 2003. Measuring soil water content with ground penetrating radar: A review. Vadose Zone Journal 2, 476-491.

Huisman, J. A., Snepvangers, J. J. J. C., Bouten, W., Heuvelink, G. B. M., 2002. Mapping spatial variation in surface soil water content: comparison of ground-penetrating radar and time domain reflectometry. Journal of Hydrology 269, 194-207.

Huisman, J. A., Sperl, C., Bouten, W., Verstraten, J. M., 2001. Soil water content measurements at different scales: accuracy of time domain reflectometry and ground penetrating radar. Journal of Hydrology 245, 48-58.

Jacob, R. W., Hermance, J. F., 2004. Assessing the precision of GPR velocity and vertical two-way travel time estimates. Journal of Environmental and Engineering Geophysics 9 (3), 143-153. 
Jadoon, K. Z., Lambot, S., Scharnagl, B., van der Kruk, J., Slob, E., Vereecken, H., 2010a. Quantifying field-scale surface soil water content from proximal gpr signal inversion in the time domain. Near Surface Geophysics 8, 483-491.

Jadoon, K. Z., Lambot, S., Slob, E., Vereecken, H., $2010 \mathrm{~b}$. Investigation of the frequency dependent antenna transfer functions and phase center position for modeling off-ground gpr. IEEE Transactions on Geoscience and Remote Sensing In press.

Jonard, F., Weihermüller, L., Jadoon, K., Schwank, M., Vereecken, H., Lambot, S., 2010. Mapping field-scale soil moisture with L-band radiometer and ground-penetrating radar over bare soil. IEEE Transactions on Geoscience and Remote Sensing In press.

Kool, J. B., Parker, J. C., 1988. Analysis of the Inverse Problem for Transient Unsaturated Flow. Water Resources Research 24, 817-830.

Lambot, S., Antoine, M., Vanclooster, M., Slob, E. C., 2006a. Effect of soil roughness on the inversion of off-ground monostatic GPR signal for noninvasive quantification of soil properties. Water Resources Research 42, W03403.

Lambot, S., Slob, E. C., Chavarro, D., Lubczynski, M., Vereecken, H., 2008. Measuring soil surface water content in irrigated areas of southern Tunisia using full-waveform inversion of proximal GPR data. Near Surface Geophysics 6, 403410 .

Lambot, S., Slob, E. C., van den Bosch, I., Stockbroeckx, B., Vanclooster, M., 2004. Modeling of ground-penetrating radar for accurate characterization of subsurface electric properties. IEEE Transactions on Geoscience and Remote Sensing 42, 2555-2568.

Lambot, S., Weihermüller, L., Huisman, J. A., Vereecken, H., Vanclooster, M., Slob, E. C., 2006b. Analysis of air-launched groundpenetrating radar techniques to measure the soil surface water content. Water Resources Research 42, W11403.

Ledieu, J., De Ridder, P., De Clercq, P., Dautrebande, S., 1986. A method of measuring soil moisture by time domain reflectometry. Journal of Hydrology 88, 319-328.

Lunt, I. A., Hubbard, S. S., Rubin, Y., 2005. Soil moisture content estimation using groundpenetrating radar reflection data. Journal of Hydrology 307 (1-4), 254-269.
Marquardt, D. W., 1963. An algorithm for leastsquares estimation of nonlinear parameters. Journal of the Society for Industrial and Applied Mathematics 11, 431-441.

Minet, J., Lambot, S., Slob, E., Vanclooster, M., 2010a. Soil surface water content estimation by full-waveform GPR signal inversion in the presence of thin layers. IEEE Transactions on Geoscience and Remote Sensing 48, 1138 - 1150.

Minet, J., Patriarca, C., Slob, E., Vanclooster, M., Lambot, S., 2010b. Characterization of layered media using full-waveform inversion of proximal GPR data. In: Proceedings of the USRI International Symposium on Electromagnetic Theory - EMTS2010. Berlin (Germany), 16-19 August 2010.

Minet, J., Wahyudi, A., Bogaert, P., Vanclooster, M., Lambot, S., 2011. Mapping shallow soil moisture profiles at the field scale using full-waveform inversion of ground penetrating radar data. Geoderma 161, 225-237.

Redman, J. D., Davis, J. L., Galagedara, L. W., Parkin, G. W., 2002. Field studies of GPR air launched surface reflectivity measurements of soil water content. In: Koppenjan, S., Hua, L. (Eds.), Proceedings of the Ninth International Conference on Ground Penetrating Radar. Santa Barbara, California, USA, pp. SPIE 4758:156-161.

Robinson, D. A., Binley, A., Crook, N., Day-Lewis, F. D., Ferre, T. P. A., Grauch, V. J. S., Knight, R., Knoll, M., Lakshmi, V., Miller, R., Nyquist, J., Pellerin, L., Singha, K., Slater, L., 2008a. Advancing process-based watershed hydrological research using near-surface geophysics: a vision for, and review of, electrical and magnetic geophysical methods. Hydrological Processes 22 (18), 3604-3635.

Robinson, D. A., Campbell, C. S., Hopmans, J. W., Hornbuckle, B. K., Jones, S. B., Knight, R., Ogden, F., Selker, J., Wendroth, O., 2008b. Soil moisture measurement for ecological and hydrological watershed-scale observatories: A review. Vadose Zone Journal 7 (1), 358-389.

Sambuelli, L., 2009. Uncertainty propagation using some common mixing rules for the modelling and interpretation of electromagnetic data. Near Surface Geophysics 7 (4, Sp. Iss. SI), 285-296.

Serbin, G., Or, D., 2003. Near-surface water content measurements using horn antenna radar: methodology and overview. Vadose Zone Journal 2, 500510 . 
Serbin, G., Or, D., 2005. Ground-penetrating radar measurement of crop and surface water content dynamics. Remote Sensing of Environment 96, 119-134.

Slob, E., Sato, M., Olhoeft, G., 2010. Surface and borehole ground-penetrating-radar developments. Geophysics 75 (5), A103-A120.

Steelman, C. M., Endres, A. L., 2010. Comparison of petrophysical relationships for soil moisture estimation using gpr ground waves. Vadose Zone Journal In press.

Topp, G. C., Davis, J. L., Annan, A. P., 1980. Electromagnetic Determination of Soil Water Content: Measurements in Coaxial Transmission Lines. Water Resources Research 16, 574-582.

van der Kruk, J., 2006. Properties of surface waveguides derived from inversion of fundamental and higher mode dispersive GPR data. IEEE Transactions on Geoscience and Remote Sensing 44 (10), 2908-2915.

van der Kruk, J., Jacob, R. W., Vereecken, H., 2010. Properties of precipitation-induced multilayer surface waveguides derived from inversion of dispersive TE and TM GPR data. Geophysics 75 (4), WA263-WA273.

Van Orshoven, J., Vandenbroucke, D., 1993. Guide de l'utilisateur d'aardewerk, base de données pédologiques, institute for land and water management, k.u. leuven, leuven, belgium. Tech. rep.

Vereecken, H., Huisman, J. A., Bogena, H., Vanderborght, J., Vrugt, J. A., Hopmans, J. W., 2008. On the value of soil moisture measurements in vadose zone hydrology: A review. Water Resources Research 44, W00D06.

Vrugt, J. A., ter Braak, C. J. F., Diks, C. G. H., Robinson, B. A., Hyman, J. M., Higdon, D., 2009. Accelerating Markov Chain Monte Carlo Simulation by Differential Evolution with SelfAdaptive Randomized Subspace Sampling. International Journal of Nonlinear Sciences and $\mathrm{Nu}$ merical Simulation 10 (3), 273-290.

Wagner, W., Blöschl, G., Pampaloni, P., Calvet, J. C., Bizzarri, B., Wigneron, J. P., Kerr, Y., 2007. Operational readiness of microwave remote sensing of soil moisture for hydrologic applications. Nordic Hydrology 38 (1), 1-20.

Weihermüller, L., Huisman, J. A., Lambot, S., Herbst, M., Vereecken, H., 2007. Mapping the spatial variation of soil water content at the field scale with different ground penetrating radar techniques. Journal of Hydrology 340, 205-216. 